\title{
Укрепление сотрудничества между ОБСЕ и Советом Европы
}

\author{
Франк Эверс, Андре Хертель, Мариэтта Кёниг*
}

\section{Аннотациия}

Совет Европы и ОБСЕ осуществляют деятельность по обеспечению соблюдения прав человека, укреплению верховенства права, демократии и стабильности в Европе. Обе организации противодействуют деградации многостороннего международного сотрудничества и нарастающему несоблюдению общих норм в Европе. В настоящей статье рассматриваются сотрудничество между Советом Европы и ОБСЕ и пути его углубления. Государствам-участникам следует оказывать обеим организациям бо́льшую политическую поддержку, обеспечить их бо́льшими кадровыми и финансовыми ресурсами. В частности, мы рекомендуем:

1. улучшить коммуникацию на политическом уровне путем активизации деятельности Координационной группы Совета Европы и ОБСЕ и возобновления встреч старших должностных лиц в формате «2+2»;

2. поощрять и финансировать более активное взаимодействие двух организаций в тех странах, где и Совет Европы, и ОБСЕ имеют присутствия на местах, обеспечивая при этом, чтобы предоставляемые ими политические и правовые рекомендации не противоречили друг другу.

Для цитирования этой публикации: Эверс Ф., Хертель А., Кёниг М. С. Укрепление сотрудничества между ОБСЕ и Советом Европы // ОБСЕ Insights 9. - Баден-Баден: Номос, 2021. URL: https://doi.org/10.5771/9783748921264-09

\section{Введение 266}

Совет Европы (CЕ) и ОБСЕ - региональные международные организации, содействующие укреплению стабильности в Европе. Они являются естественными партнерами с прочными и давними отношениями. Обе организации содействуют обеспе-

* Франк Эверс, доктор наук, Институт исследований проблем мира и политики безопасности при Университете Гамбурга (IFSH), Германия, evers@ifsh.de

Андре Хертель, доктор наук, Институт исследований проблем мира и политики безопасности при Университете Гамбурга (IFSH), Германия, haertel@ifsh.de

Мариэтта С. Кёниг, Офис Генерального секретаря, Секретариат ОБСЕ, Вена, Австрия,

Marietta.Koenig@gmx.de

В настоящей статье авторы высказывают личную точку зрения, которая не обязательно отражает официальную позицию СЕ, ОБСЕ или их государств-членов и государств-участников. 
чению соблюдения прав человека и основных свобод, укреплению демократии и верховенства права.

В Европе и за ее пределами все хуже обстоит дело с соблюдением норм, позволивших наладить диалог, укрепить безопасность и доверие между государствами и обществами после окончания конфликта между Востоком и Западом. Доверие общества к демократическим институтам падает, а политическая радикализация нарастает. В этой ситуации можно было бы ожидать, что правительства будут поддерживать тесное взаимодействие Совета Европы и ОБСЕ. Однако несмотря на то, что в последние два десятилетия вопросы укрепления сотрудничества между двумя организациями неоднократно были предметом обсуждений, они до сих пор так и не стали приоритетными для государств-членов СЕ и государств-участников ОБСЕ.

Настоящая статья преследует двойную цель: проанализировать нынешнее состояние сотрудничества между СЕ и ОБСЕ и предложить пути его углубления. В статье мы исходим из того, что расширение взаимодействия СЕ и ОБСЕ способствовало бы смягчению остроты некоторых из стоящих перед Европой проблем.

Мы считаем, что необходимо расширить сотрудничество между экспертами двух организаций и дополнить его более содержательным взаимодействием на руководящем уровне, в частности, в рамках Координационной группы Совета Европы и ОБСЕ, общение в которой носит преимущественно ритуальный характер. Мы предлагаем также вернуться к идее проведения встреч старших должностных лиц в формате «2+2» и наладить более тесное взаимодействие в странах, в которых обе организации имеют свои представительства. Государства-члены Европейского Союза должны лучше использовать возможности ОБСЕ и СЕ как двух центральных организаций, осуществляющих деятельность в интересах укрепления стабильности в Европе.

Статья основана на серии интервью с представителями двух организаций, проведенных в Страсбурге, Гааге, Вене и Варшаве в период с сентября по декабрь 2017 года и в 2020 году. Она также опирается на анализ документов, принятых в целях регулирования отношений между двумя организациями и придания им официального характера.

В первом разделе рассматривается сложившаяся к настоящему времени практика сотрудничества между ОБСЕ и СЕ. Во втором - политические и структурные проблемы, препятствующие его углублению. В третьем, заключительном разделе государствам-участникам и исполнительным структурам двух организаций предлагаются рекомендации по углублению сотрудничества.

\section{Взаимодействие ОБСЕ и Совета Европы}

И СЕ, и ОБСЕ - каждая организация по-своему - осуществляют деятельность, направленную на укрепление безопасности и стабильности в Европе. ОБСЕ - круп- 
нейшая в мире региональная организация, действующая в соответствии с главой VIII Устава ООН. Она представляет собой инклюзивный форум для ведения переговоров. 57 государств-участников регулярно обсуждают вопросы безопасности в Постоянном совете и в рамках Форума по сотрудничеству в области безопасности в Вене. ОБСЕ имеет разветвленную сеть присутствий на местах и осуществляет наиболее масштабную в Европе деятельность по регулированию конфликтов.

Совет Европы, в состав которого входят 47 государств, в свою очередь вносит вклад в поддержание стабильности в Европе своей деятельностью по обеспечению соблюдения права человека, укреплению демократию и верховенства права, в частности, путем принятия и содействия претворению в жизнь соответствующих международных соглашений и конвенций. Европейская конвенция о защите прав человека и основных свобод 1950 года и более 220 других конвенций и международноправовых актов наряду с обеспечивающим их реализацию обширным аппаратом помогают защищать права тех, кто находится под юрисдикцией государств-членов Совета Европы. Правовые инструменты СЕ и принятые в рамках ОБСЕ и устанавливающие определенные нормы политические обязательства, а также широкое присутствие последней на местах хорошо дополняют друг друга 267.

У двух организаций прочные и давние отношения. Они неоднократно подчеркивали «гибкий и прагматичный характер» ${ }^{268}$ своего сотрудничества и твердое намерение «дополнять и подкреплять друг друга» ${ }^{269}$. На уровне экспертов и в процессе осуществления конкретной деятельности организации тесно взаимодействуют в рамках отношений, основанных на взаимодополняемости, транспарентности, демократической подотчетности и взаимном признании специфических задач каждой из организаций, различий в членском составе и автономии.

Однако углубление и расширение сотрудничества затруднено в силу отношений, сложившихся на руководящем и политическом уровнях. Коммуникация на этих уровнях весьма редка и носит преимущественно ритуальный характер. Аналогичная ситуация складывается на местах. Здесь тоже есть резервы для улучшения взаимодействия и координации.

\section{Формы сотрудничества}

Гибкость и прагматизм - руководящие принципы четырех ключевых документов (см. вставку), официально регулирующих сотрудничество между СЕ и ОБСЕ с целью избежать дублирования в их деятельности и наилучшим образом использовать их сравнительные преимущества. 


\section{Документы, регулирующие сотрудничество между Советом Европы и ОБСЕ}

1. СЕ, Отношения между Советом Европы и ОБСЕ: Общий каталог механизмов сотрудничества, Секретариат ОБСЕ, SEC.GAL/30/00, 4 апреля 2000 года, Секретариат СЕ, СM(2000)52, 25 апреля 2000 года.

2. ОБСЕ, Расширение сотрудничества между Организацией по безопасности и сотрудничеству в Европе (ОБСЕ) и Советом Европы (CE), Решение Постоянного совета РC.DEC/637, 2 декабря 2004 года.

3. ОБСЕ, Сотрудничество между Организацией по безопасности и сотрудничеству в Европе (ОБСЕ) и Советом Европы, Решение Постоянного совета PC.DEC/670, 28 апреля 2005 года.

4. СЕ, Декларация о сотрудничестве между Организацией по безопасности и сотрудничеству в Европе и Советом Европы, Варшавский саммит, 17 мая 2005 года.

Этими документами определены формы взаимодействия, среди которых:

- взаимное представительство на заседаниях принимающих решения органов и парламентских ассамблей, а также назначение контактных лиц;

- Координационная группа, учрежденная в 2004 году ${ }^{270}$ для проведения регулярных совещаний на руководящем уровне для обсуждения сотрудничества на четырех официально согласованных тематических направлениях (потенциал группы обсуждается ниже);

- совещания высокого уровня в формате «2+2» с участием действующего Председателя ОБСЕ и Председателя Комитета министров СЕ, двух генеральных секретарей, а также руководителей институтов и старших должностных лиц;

- совещания в формате «2+2» на уровне старших должностных лиц, парламентские совещания, совместные совещания с участием экспертов из столиц и представителей секретариатов (оба формата «2+2» в настоящее время не используются, но могут быть использованы - см. рекомендации ниже);

- трехсторонние совещания высокого уровня с участием председателей и генеральных секретарей ОБСЕ и СЕ, а также Генерального директора отделения ООН в Женеве и других представителей (проводились ежегодно с 1993 по 2011 год) $)^{271}$;

- взаимодействие между институтами СЕ и ОБСЕ в рамках согласованных направлений сотрудничества;

- сотрудничество между секретариатами и обмен информацией;

- проведение рабочих совещаний по мере необходимости, а также совещаний между отделами секретариатов ${ }^{272}$.

На протяжении многих лет двумя организациями был согласован ряд рабочих договоренностей, меморандумов о взаимопонимании и обменов письмами, преследую- 
щих цель содействовать взаимодействию между ними. Один из недавних примеров - обмен письмами между директором Бюро ОБСЕ по демократическим институтам и правам человека (БДИПЧ) и Генеральным секретарем СЕ в 2019 г., которыми определялись направления сотрудничества.

Согласованные формы сотрудничества используются на разных организационных уровнях с разной степенью эффективности: достаточно редко и негибко на более высоком политическом уровне (в Координационной группе), интенсивно на рабочем уровне во взаимодействии между различными структурами двух организаций и неравномерно - на местах.

\section{Официальные формы коммуникации на высоком уровне}

На политическом уровне коммуникация между СЕ и ОБСЕ сталкивается с проблемами. Учрежденная в 2004 году Координационная группа представляет собой официальный формат проведения совещаний двух организаций на высоком уровне. Группа собирается два раза в год поочередно в Страсбурге и Вене (13 ноября 2020 года группа собралась в 32-й раз и во второй раз - в режиме онлайн из-за ограничений в связи с пандемией COVID-19). Некоторые считают, что первоначальная договоренность о том, что «заседания Координационной группы будут проводиться по мере необходимости, но не реже одного раза в шесть месяцев» ${ }^{273}$, обязывает членов группы общаться чаще. В зависимости от рассматриваемых вопросов со стороны Совета Европы в совещаниях участвуют Председатель Комитета министров, представители Бюро заместителей министров, председатель группы докладчиков по внешним связям и сотрудники секретариата. Со стороны ОБСЕ в них участвуют представители «тройки» председателей, сотрудники секретариата, включая бюро Специального представителя и координатора по борьбе с торговлей людьми, и институты, в частности Верховный комиссар по делам национальных меньшинств (ВКНМ) и БДИПЧ.

Официальная повестка дня заседаний группы весьма ритуальна и ограничивается четырьмя согласованными направлениями сотрудничества, а именно вопросами: а) борьбы с терроризмом, б) борьбы с торговлей людьми, в) поощрения терпимости и недискриминации и г) защиты прав лиц, принадлежащих к национальным меньшинствам ${ }^{274}$. Это не оставляет места для быстрого реагирования на те или иные события или процессы. Первоначально перечисленные направления были определены в качестве отправной точки для обсуждений, однако их перечень так и не был расширен. Данное обстоятельство объясняется главным образом отсутствием консенсуса государств-участников ОБСЕ, некоторые из которых возражают против включения в повестку дня тех или иных вопросов. Даже в рамках перечисленных четырех направлений существуют острые разногласия по таким темам, как вопросы меньшинств, толерантность и недискриминация, а также гендерная проблематика. 


\section{Гибкое взаимодействие на рабочем уровне}

Сотрудничество между СЕ и ОБСЕ на рабочем уровне менее структурировано, но гораздо более развито, чем в рамках Координационной группы. Старшие должностные лица обеих организаций высоко оценивают отличные связи на экспертном уровне. Отмечается высокий уровень взаимной осведомленности о деятельности, особенно в отношениях между БДИПЧ и Европейской комиссией за демократию через право, более известной как Венецианская комиссия. Совместная деятельность часто осуществляется в соответствии с согласованным порядком. Ряд полевых операций ОБСЕ обменивается информацией с СЕ и организует совместные мероприятия и проекты, относящиеся к их соответствующим мандатам. Однако такая деятельность редко обсуждается на заседаниях Координационной группы или отражается в отчетах, представляемых государствам-членам и государствам-участникам.

БДИПЧ возглавляет совместные с Парламентской ассамблеей Совета Европы (ПАСЕ) и Парламентской ассамблеей ОБСЕ миссии по наблюдению за выборами. Парламентские ассамблеи часто проводят совместные встречи, и сотрудничество между ними (а также с Европейским парламентом и менее регулярное сотрудничество с Парламентской ассамблеей Организации Североатлантического договора и Конгрессом местных и региональных властей Совета Европы) оценивается как отличное. Наблюдение за выборами - наиболее знаковый вид совместной деятельности, заметный для широкой общественности во многих странах.

БДИПЧ и Комиссар СЕ по правам человека, который стал постоянным гостем на форумах ОБСЕ, проводят тематические консультации. Институты ОБСЕ поддерживают контакты с Конгрессом местных и региональных властей, Конференцией международных неправительственных организаций и Европейским судом по правам человека. Должностные лица Совета Европы подчеркивают передовую практику сотрудничества, такую как взаимные приглашения представителей руководящего звена ОБСЕ на совещания высокого уровня, участие ОБСЕ в работе комитетов СЕ и их вспомогательных органов, а также взаимодействие с присутствиями ОБСЕ на ме$\operatorname{cтах~}^{275}$.

Институты и структуры двух организаций систематически используют решения, оценки, руководства и другие публикации друг друга в качестве правовых и политических ориентиров. У Венецианской комиссии и БДИПЧ давно сложилась основанная на соглашении о сотрудничестве традиция совместно составлять заключения и руководящие принципы, например, по вопросам свободы религии, мирных собраний и ассоциаций ${ }^{276}$. Сотрудничество особенно интенсивно в тех сферах, в которых разработаны руководящие принципы.

БДИПЧ сотрудничает не только с Венецианской комиссией в том, что касается проведения обзора и оценки законодательства, или с ПАСЕ по вопросам выборов, но и с секретариатом Совета Европы по представляющим взаимный интерес темам. К ним относятся поощрение терпимости и недискриминации и защита прав челове- 
ка (в том числе защита прав таких меньшинств, как цыгане - рома и синти), поддержка правозащитной деятельности и борьба с преступлениями на почве ненависти. Эксперты этих двух институтов регулярно встречаются, обмениваются информацией, докладами и участвуют в общих мероприятиях. В своей деятельности по укреплению потенциала БДИПЧ систематически использует страновые отчеты и политические рекомендации Европейской комиссии по борьбе с расизмом и нетерпимостью (ЕКРН), а ЕКРН использует в своих страновых отчетах данные БДИПЧ о преступлениях на почве ненависти. Консультативный комитет Рамочной конвенции о защите национальных меньшинств (РКЗНМ) часто ссылается в своих страновых отчетах на данные БДИПЧ о преступлениях на почве ненависти, а также на тематические рекомендации и руководящие принципы Верховного комиссара ОБСЕ по делам национальных меньшинств. В свою очередь, ВКНМ использует заключения Консультативного комитета Рамочной конвенции о защите национальных меньшинств и отчеты Комитета экспертов Европейской хартии региональных языков или языков меньшинств. Установившейся практикой стали визиты ВКНМ в Страсбург и Венецию для обсуждения с руководящими сотрудниками вопросов, связанных с меньшинствами в тех или иных странах.

Обмен письмами между директором БДИПЧ Ингибьорг Солрун Гисладоттир и Генеральным секретарем Совета Европы Марией Пейчинович Бурич в ноябре 2019 года позволил привлечь внимание групп экспертов к направлениям сотрудничества между БДИПЧ и СЕ 277 . Есть примеры аналогичной переписки между СЕ и ВКНМ и Представителем ОБСЕ по вопросам свободы средств массовой информации.

\section{Неравномерное сотрудничество на местах}

Краеугольный камень сотрудничества ОБСЕ и СЕ - взаимодействие на местах. У обеих организаций много представительств на местах. У Совета Европы - 17 офисов различного профиля в разных регионах, а также четыре бюро по связям и еще одно бюро в Париже. Присутствия СЕ есть в странах, в которых ОБСЕ не представлена или не имеет постоянного представительства, таких как Турция и три государства Южного Кавказа. По состоянию на 2020 год у ОБСЕ было 16 присутствий на местах, в том числе пять - в Центральной Азии, где Совет Европы не представлен. Три основных института ОБСЕ также ведут работу на местах. В то же время обе организации имеют присутствия в странах Юго-Восточной и Восточной Европы.

Сотрудничество между присутствиями ОБСЕ и отделениями СЕ в различных странах развивалось неравномерно. В Украине, где обе организации расширили свое присутствие после 2013-2014 годов, их взаимодействие относительно развито. На основе меморандума о сотрудничестве организации раз в два года проводят совещания и интегрировали свою деятельность в рамках совместного плана действий $\mathrm{EC}$, Совета Европы и ОБСЕ. Здесь существует прекрасный синергетический эф- 
фект, в частности, в том, что касается реформы системы правосудия. Совет Европы и координатор проектов ОБСЕ в Украине совместно оказывают содействие реформированию Генеральной прокуратуры, а ОБСЕ, в частности, использует в своих программах повышения квалификации опыт судей Европейского суда по правам человека (ЕСПЧ). В других же странах сотрудничеству необходимо придать более систематический характер. Так обстоит дело, например, в Боснии и Герцеговине, где две организации имеют почти одинаковые приоритеты (предусмотренные планом действий СЕ и мандатом миссии ОБСЕ) и работают с одними и теми же партнерами и донорами. В целом сотрудничество на местах затруднено прежде всего там, где сложилась деликатная политическая обстановка, замедлился процесс интеграции в ЕС или принимающие государства не идут на сотрудничество с присутствиями ОБСЕ и дистанцируются от их деятельности. Это связано с тем, что присутствие ОБСЕ в стране зачастую воспринимается как стигма, поскольку считается, что такие присутствия развертываются в странах с дефицитом демократии или внутренними конфликтами.

\section{Препятствия для более тесного взаимодействия}

Более десяти лет вновь и вновь прилагались усилия по сближению Совета Европы и ОБСЕ. Конкретные предложения были сформулированы в 2012 г. в документе СЕ, озаглавленном «Отношения между Советом Европы и ОБСЕ: путь вперед» ${ }^{278}$. На сегодняшний день это - последняя серьезная попытка обсуждения данного вопроса. Однако организации так и не смогли реализовать предлагавшиеся меры. С одной стороны, это объясняется сдержанностью на политическом уровне, а с другой структурными различиями между организациями.

\section{Сдержанное отношение на высоком уровне}

В 2012 году ${ }^{279}$ CЕ предложил договориться о регулярном принятии совместных решений и возобновить практику взаимных приглашений. После года обсуждений ОБСЕ дала очень осторожный ответ, сославшись на то, что она отдает предпочтение «прагматичному, эффективному, ориентированному на достижение конкретных целей и результатов сотрудничеству», основанному на взаимодействии экспертов, а также конкретному сотрудничеству на местах ${ }^{280}$. Последовавшее за этим предложение бельгийского Председателя Комитета министров СЕ начать очередные консультации между организациями не было в достаточной степени согласовано в Совете Европы и в конечном итоге не было вынесено на обсуждение с ОБСЕ ${ }^{281}$. Бельгийский Председатель организовал внеочередное совещание Совета Европы и ОБСЕ на 
высоком уровне в кулуарах 125-й сессии Комитета министров в Брюсселе. Однако после этого совещания Совета Европы и ОБСЕ на высоком уровне больше не проводились.

Взаимное предоставление права выступить на встречах Совета министров ОБСЕ и на заседаниях Комитета министров СЕ было предметом разногласий. Как правило, на соответствующих заседаниях международным организациям слово предоставляется после того, как выступят представители государств-членов или государств-участников. Возможность выступления Генерального секретаря СЕ на встрече Совета министров ОБСЕ зависит от консенсуса государств-участников по вопросу о порядке проведения ежегодной встречи. В связи с отсутствием договоренности о порядке проведения встреч Совета министров ОБСЕ в Белграде в 2015 году и Гамбурге в 2016 году СЕ и другим международным организациям слово предоставлено не было. В Белграде Сербия как действующий Председатель предоставила слово Генеральному секретарю СЕ Турбьёрну Ягланду на обеде министров. С 2016 года Совет Европы на встречах Совета министров ОБСЕ представлен руководителем венского офиса СЕ по связям.

Генеральный же секретарь ОБСЕ Томас Гремингер принял участие в юбилейной церемонии по случаю 70-летия Совета Европы и выступил на 129-й сессии Комитета министров СЕ в 2019 году - после четырех лет неучастия Генерального секретаря ОБСЕ в этом ежегодном мероприятии. На министерских сессиях СЕ в 2018 и 2020 годах ОБСЕ представлял сотрудник офиса Генерального секретаря.

В то же время хорошо функционирует институт взаимного представительства СЕ в Постоянном совете ОБСЕ и ОБСЕ - на заседаниях заместителей министров Совета Европы. Однако неоднократные запросы со стороны СЕ о возможности постоянного доступа к заседаниям Постоянного совета остались без ответа, поскольку государства-участники ОБСЕ не смогли достичь консенсуса по этому вопросу. В 2014 году Швейцария как Председатель ОБСЕ ввела практику в начале каждого заседания принимающих решения органов объявлять представителей СЕ и других аккредитованных при ОБСЕ международных организаций своими гостями. С тех пор каждая председательствующая в ОБСЕ страна продолжает эту практику.

Усилия по организации более частых двусторонних встреч генеральных секретарей двух организаций принесли свои плоды только после их смены в 2017 (ОБСЕ) и 2019 (СЕ) годах. Генеральные секретари Гремингер и Пейчинович Бурич уделяли повышенное внимание отношениям между их организациями и использовали для встреч различные форматы. Генеральный секретарь СЕ Пейчинович Бурич выступила в Постоянном совете ОБСЕ в декабре 2019 и в декабре 2020 года. Однако после того как в июле 2020 года мандат Генерального секретаря ОБСЕ не был продлен, интенсивное взаимодействие между двумя генеральными секретарями прервалось.

Проведение регулярных совещаний старших должностных лиц было прекращено в 2010 году, так как они больше не считались нужными. С точки зрения ОБСЕ, 
необходимость в них отпала после начала проведения совещаний Координационной группы ОБСЕ-СЕ. Руководители отделов внешнего сотрудничества или внешних связей по-прежнему встречаются по мере необходимости для обсуждения содержательных вопросов повестки дня и подготовки совещаний на высоком уровне.

Неоднократно рассматривался вопрос о придании диалогу в рамках Координационной группы более предметного характера, в частности, путем расширения повестки дня, ограниченной четырьмя пунктами. С точки зрения Страсбурга, именно ОБСЕ выступает против ее расширения. В Вене же обычно отмечают, что государстваучастники, как правило, хотят все держать под своим контролем и не хотят, чтобы структуры ОБСЕ действовали самостоятельно. С другой стороны, ряд предыдущих председателей Постоянного совета ОБСЕ и Бюро заместителей министров СЕ пользовались предоставленной им во время их пребывания в должности возможностью дополнить совещания Координационной группы неформальным обсуждением выходящих за рамки официальной повестки дня вопросов, тем самым превратив эти совещания, по свидетельству участников, в «чрезвычайно плодотворные мероприятия». Это дает основания полагать, что повышение эффективности работы Координационной группы возможно путем расширения не столько стандартной повестки дня, сколько - неофициального обмена мнениями (см. наши рекомендации ниже).

В целом нежелание (в частности, ряда государств-участников ОБСЕ) предоставить СЕ право выступать на встречах Совета министров ОБСЕ и рассмотреть возможность ослабления жестких рамок формального общения в рамках Координационной группы не позволяет придать коммуникации на более высоком политическом уровне систематический характер. По многим вопросам общение и содержательное сотрудничество между организациями осуществляется на более низком уровне чем ближе к рабочему уровню, тем конструктивнее участие в нем экспертов.

\section{Структурные различия}

Усилиям по налаживанию более систематического сотрудничества между ОБСЕ и СЕ препятствуют не только отсутствие политической воли, но и структурные различия. ОБСЕ - это некарьерная организация со слабым бюрократическим аппаратом, который находится под пристальным вниманием делегаций в Вене. Политическое руководство осуществляется действующим Председателем, который, однако, всего лишь первый среди равных в кругу своих коллег министров. Генеральный секретарь выступает лишь в качестве представителя действующего Председателя и главного административного должностного лица организации. У него нет прямых полномочий в отношении трех институтов ОБСЕ - БДИПЧ, ВКНМ и Представителя по вопросам свободы СМИ - и представительств на местах, которые подотчетны непосредственно директивным органам организации (и, таким образом, делегациям). 
Парламентская ассамблея ОБСЕ не является интегральной частью организации, и ее депутаты не имеют полномочий, которыми обладают их коллеги из ПАСЕ.

В Совете же Европы (который является карьерной организацией) важную роль играют Генеральный секретарь и бюрократический аппарат, а также депутаты и делегации в ПАСЕ. ЕСПЧ является независимым судебным органом. Решения органов СЕ и постановления Суда имеют юридическую силу во всех странах Совета Европы.

Различия в порядке принятия решений зачастую приводят к тому, что организации занимают разные позиции. Правило консенсуса усложняет политический диалог в ОБСЕ, а принимаемые решения нередко основываются на наименьшем общем знаменателе позиций государств-участников. Решения в ОБСЕ - это политические обязательства, их невыполнение не влечет за собой правовые последствия. СЕ и его органы принимают решения, имеющие обязательную юридическую силу в соответствии с международным правом, большинством голосов. Таким образом, позиции тех или иных государств-членов могут быть отвергнуты, как это часто происходило, в частности, с Россией по вопросам, касающимся Украины. Лишение России права участвовать в голосовании в Парламентской ассамблее СЕ после аннексии Крыма в 2014 году вызвало споры, но подобное решение в принципе немыслимо в инклюзивной, основанной на консенсусе ОБСЕ.

Различия есть и в членском составе организаций, хотя в основном он совпадает. Россия участвует в обеих организациях, в то время как Соединенные Штаты Америки (США), Беларусь, Канада, Святой Престол, пять стран Центральной Азии и Монголия не входят в $\mathrm{CE}^{282}$. Однако США и Канада на постоянной основе представлены в Совете Европы в качестве наблюдателей и внимательно следят за обсуждениями в нем.

В своей совокупности специфические особенности двух организаций - различия в характере обязательств (юридически обязывающие и обеспеченные правовыми санкциями или же политические), порядке принятия решений и степени автономности аппаратов - осложняют сотрудничество между ними. В особенности - на политическом уровне из-за сложности согласования общих позиций по деликатным вопросам, несмотря на сотрудничество на рабочем уровне.

\section{Выводы и рекомендации}

СЕ и ОБСЕ, две организации, каждая из которых обладает собственными инструментами и сравнительными преимуществами, стремятся содействовать укреплению стабильности в Европе. Обе ставят своей целью обеспечение соблюдения прав человека и основных свобод, укрепление демократии и верховенства права. В условиях все более частого нарушения общих норм и политической радикализации, которую 
переживает Европа, укрепление сотрудничества между двумя организациями имеет важное значение.

Для этого требуется нечто большее, чем заявления государств о приверженности использованию многосторонних институтов. Необходимо, чтобы ключевые государства играли более активную роль. Это относится, конечно, не только, но в особенности к странам-членам и институтам ЕС. Для ЕС и Совет Европы (например, в процессе вступления новых членов), и ОБСЕ (например, в деле урегулирования конфликтов, таких как в Украине и вокруг нее, или в регионах, в которых влияние и возможности ЕС ограничены) являются ценными партнерами. Проблема заключается в том, чтобы перевести официальные соглашения о сотрудничестве в практическую плоскость. В докладе Группы докладчиков СЕ 2012 года эта идея изложена кратко: «Вероятно, нет большой необходимости в подготовке дополнительных обязывающих конвенций. Основное внимание должно быть уделено выполнению уже подписанных» ${ }^{283}$. Ниже мы предлагаем небольшие практические шаги по улучшению сотрудничества между Советом Европы и ОБСЕ.

\section{Совершенствование коммуникации на высоком уровне}

Углубление и расширение сотрудничества между ОБСЕ и СЕ во многом сдерживается в силу редкого и преимущественно ритуального общения на высоком и политическом уровнях. По этой причине государствам следует содействовать улучшению коммуникации между двумя организациями на политическом уровне и, в частности, приданию более содержательного характера обсуждениям в ходе проводимых раз в два года совещаний Координационной группы. Исходя из нереалистичности изменения официального порядка проведения этих совещаний, следует рассмотреть возможность расширения содержания обсуждений за счет проведения неформальных консультаций. В этой связи мы предлагаем следующее:

- Во-первых, следует рассмотреть вопрос о проведении дополнительных встреч экспертов во время совещаний Координационной группы. Представители обеих организаций положительно оценивают опыт проведения в последние годы таких неофициальных консультаций в целях оптимизации совместной деятельности. На параллельных совещаниях можно было бы обсуждать вопросы, выходящие за рамки четырех официальных пунктов повестки дня, такие как миграция, недискриминация, молодежь и безопасность, свобода средств массовой информации и безопасность журналистов. На них также могли бы обсуждаться такие актуальные вопросы, как реагирование на пандемию COVID-19 и деятельность на местах. Кибербезопасность и искусственный интеллект, их влияние на демократию и права человека - еще одна область для обсуждений, которая может быть перспективной с точки зрения будущего сотрудничества. 
- Во-вторых, в рамках пункта повестки дня «любые другие вопросы» Координационной группе можно было бы поручить разработку общих тематических приоритетов в рамках подготовки к совещаниям на высоком уровне и консультациям с государствами-членами и государствами-участниками.

- В-третьих, следует подготовить почву для возобновления совещаний в формате «2+2» на уровне старших должностных лиц, как это предусматривалось в 2000 году ${ }^{284}$, с целью конкретизации обсуждаемых вопросов и согласования дальнейших действий. В 2021 году инициативу по возобновлению таких встреч могла бы взять на себя Швеция как действующий Председатель ОБСЕ при поддержке членов «тройки» ОБСЕ (Албании и Польши) и «тройки» председателей Комитета министров СЕ (Германии, Венгрии и Италии).

\section{Поддержка взаимодействия на местах}

Хотя количество присутствий СЕ и ОБСЕ на местах примерно одинаково, они играют разную роль в этих организациях. Главным оперативным центром Совета Европы является его штаб-квартира, в то время как более трех четвертей сотрудников ОБСЕ работают на местах. СЕ с его конвенциями, компетенцией в правовой сфере, механизмами мониторинга и солидными финансовыми ресурсами - ценный партнер ОБСЕ с ее возможностями быстрого реагирования и ноу-хау, а также деятельностью в таких областях, как регулирование конфликтов и демократизация.

Взаимодополняющий характер двух организаций открывает возможности для координации и сотрудничества в интересах достижения общих политических целей. Систематическое взаимодействие между ОБСЕ и СЕ на местах по конкретным вопросам и с учетом потребностей принимающих стран не было бы чем-то новым ${ }^{285}$. Сотрудничество ОБСЕ и СЕ в Украине - хороший пример, которому можно следовать. В этой связи мы предлагаем следующее:

- Во-первых, государствам следует поощрять и финансировать более активное взаимодействие между ОБСЕ и СЕ в странах, в которых у обеих организаций есть присутствия. ОБСЕ обладает богатым опытом работы и персоналом на местах, а СЕ обладает компетенциями в правовой сфере и значительными финансовыми ресурсами.

- Во-вторых, ЕС следует использовать свою роль в обеих организациях для систематического укрепления взаимодействия ОБСЕ и СЕ на местах. У него особые отношения с CE, опирающиеся на широкий «механизм для расширенного сотрудничества и политического диалога» и связанный с ним комплекс соглашений и рабочих планов 286 . ЕС также предпринял шаги для более тесного сотрудничества с ОБСЕ ${ }^{287}$. Президенты и председатели ЕС, СЕ и ОБСЕ могли бы выступить с совместной политической инициативой по обсуждению путей укреп- 
ления их совместной деятельности на местах и включить трехсторонние усилия в стратегическое видение европейской безопасности.

- В-третьих, двум организациям следует обеспечить, чтобы предоставляемые ими политические и правовые рекомендации не противоречили друг другу. ОБСЕ следует активнее использовать юридическую терминологию Совета Европы, в то время как СЕ следует более систематически использовать документы ОБСЕ, касающиеся проведения демократических выборов, защиты основных прав, верховенства права, а также толерантности и недискриминации. Обеспечение согласованности их рекомендаций повысит легитимность обеих организаций и политическую отдачу от их деятельности на местах.

В настоящей статье авторы высказывают личную точку зрения, которая не обязательно отражает официальную позицию СЕ, ОБСЕ или их государств-членов и государств-участников.

\section{Примечания}

266 Авторы хотели бы поблагодарить своих многочисленных собеседников и рецензентов за ценные замечания и советы.

267 Что касается масштабов деятельности, то общий годовой бюджет СЕ составляет около 496 млн евро, не считая добровольные взносы, а штат насчитывает около 2500 сотрудников, в то время как ОБСЕ имеет годовой бюджет около 139 млн евро, не считая внебюджетные средства, а штатный персонал насчитывает 2880 сотрудников. См.: The Council of Europe in brief: Budget // Официальный сайт Совета Европы. URL: https://www.coe.int/en/web/abou t-us/budget?desktop=true; Approval of the 2020 Unified Budget. PC.DEC/1369, 28 May 2020 // Официальный сайт ОБСЕ. URL: https:/www.osce.org/permanent-council/453804; Who we are: Funding and budget // Официальный сайт ОБСЕ. URL: https://www.osce.org/funding-andbudget.

268 OSCE/CoE, Relations Between the Council of Europe and the OSCE: Common Catalogue of Cooperation Modalities, SEC.GAL/30/00, 4 April 2000 and CM(2000)52, 25 April 2000 // Официальный сайт Совета Европы. URL: https://rm.coe.int/CoERMPublicCommonSearchServices /DisplayDCTMContent?documentId=0900001680599d8d.

269 Постоянный совет. Решение № 637. Расширение сотрудничества между Организацией по безопасности и сотрудничеству в Европе (ОБСЕ) и Советом Европы (CE). PC.DEC/637, 2 декабря 2004 // Официальный сайт ОБСЕ. URL: https://www.osce.org/files/f/documents/7/1/1 4736.pdf.

270 Там же.

271 Последнее такое совещание состоялось 21 сентября 2011 года в Нью-Йорке в кулуарах Генеральной Ассамблеи ООН. Оно было организовано председательствовавшей тогда в ОБСЕ Литвой. Следующее совещание должен был организовать СЕ, но в 2012-2014 годах его председатели не смогли определить ни время и место, ни повестку дня для встречи в формате «2+2». В 2015 г. было проведено совещание высокого уровня в формате «2+3» (включая Боснию и Герцеговину, готовившуюся к председательству в СЕ), но такие встречи больше не проводились. 
272 OSCE/CoE, Relations Between the Council of Europe and the OSCE: Common Catalogue of Cooperation Modalities.

273 ОБСЕ, Постоянный совет. Решение № 637.

274 Декларация о сотрудничестве между Советом Европы и Организацией по безопасности и сотрудничеству в Европе, 17 мая 2005 // Официальный сайт Совета Европы. URL: https://w ww.coe.int/t/dcr/summit/20050517_decl_conjointe_RU.asp

275 CoE Directorate of External Relations, OSCE: Background Information, 6 November 2017.

276 См.: Венецианская комиссия. Основные права // Официальный сайт Совета Европы. URL: https://www.venice.coe.int/WebForms/pages/?p=02_Rights\&lang=RU.

277 К таким направлениям сотрудничества относятся терпимость и недискриминация, миграция, верховенство права, демократическое управление, проблемы рома и синти, гендерное равенство, а также распространение информации о демократических ценностях и правах человека.

278 Relations Between the Council of Europe and with the OSCE: The Way Forward. GREXT(2012)11-rev, 25 October 2012 // Официальный сайт Совета Европы. URL: https://search .coe.int/cm/Pages/result_details.aspx?ObjectID=09000016805c9b83.

279 Ibid.

280 Igor Prokopchuk, Chairperson of the OSCE Permanent Council. Letter to the Permanent Representative of Austria to the Council of Europe/Chairperson of the Council of Europe's Committee of Ministers' Deputies. CIO.GAL/186/13, 30 December 2013.

281 Belgian Chair of the CoE's Committee of Ministers. Possibilities for enhanced cooperation between the Council of Europe (CoE) and the Organization for Security and Cooperation in Europe (OSCE), January 2015.

282 СЕ поддерживает конструктивные рабочие отношения с пятью центральноазиатскими странами. Казахстан и Кыргызстан были включены в Политику добрососедства СЕ, инициированную в 2011 году. В 2007 году Венецианская комиссия и центральноазиатские страны установили сотрудничество, при этом проектное финансирование было предоставлено Европейским Союзом и отдельными странами-членами СЕ. В январе 2020 года с пятью государствами было заключено соглашение о реализации совместной программы «Верховенство права в Центральной Азии». В том же месяце Казахстан присоединился к Группе государств Совета Европы против коррупции (GRECO).

283 The Council of Europe and the OSCE: Enhancing Cooperation and Complementarity Through Greater Coherence. Rapporteur Group on External Relations (GR-EXT), Strasbourg, 19 January 2012. Progress report on a study by Professor Dr. juris Geir Ulfstein, University of Oslo, DD(2012)40, 16 January 2012. Этот доклад связан с докладом Ульфстейна (DPP (2012)1, 23 марта 2012), опубликованному позднее под тем же названием // Официальный сайт Совета Европы. URL: https://rm.coe.int/CoERMPublicCommonSearchServices/DisplayDCTMConte nt?documentId=0900001680599dd7.

284 OSCE/CoE, Relations Between the Council of Europe and the OSCE: Common Catalogue of Cooperation Modalities.

285 См., к примеру: Igor Prokopchuk. Op. cit.

286 См.: Memorandum of Understanding between the Council of Europe and the European Union, 11 and 23 Мау 2007 // Официальный сайт Совета Европы. URL: https://rm.coe.int/1680597b

32. К настоящему времени ЕС профинансировал несколько сотен совместных программ с CE.

287 Общее понимание важности укрепления сотрудничества между ЕС и ОБСЕ нашло отражение в письмах, которыми 22 июня 2018 года обменялись высокий представитель ЕС Федерика Могерини и генеральный секретарь ОБСЕ Томас Гремингер. 